\title{
Estimating the Output GAP for Lebanon: A Production Function methodology
}

\author{
Prof. Latifa Ghalayini ${ }^{a^{*}}$ \\ ${ }^{a}$ Lecturer, Lebanese University, Economic Sciences and Business Administration Faculty, Ighalayini@ul.edu.Ib \\ ${ }^{*}$ Corresponding author.
}

Received: 23 September 2018, accepted: 8 October 2018, published: 2 Marc h2019

\begin{abstract}
This paper estimates the output Gap for Lebanon to analyze the economic policy and to judge the stance of the economy. Therefore, a Cobb-Douglas production function is estimated for the period $Q_{1} 1998$ to $Q_{4} 2015$ and potential output calculated by substituting for potential levels of the factors in the estimated production function. The calculation of potential labor required the calculation of the NAIRU. This paper calculates therefore three types of NAIRU. The results of output gap calculations show that the Lebanese economy is working over its capacity and that it hits his limits. Furthermore, findings show that the labor market is characterized by high levels of NAIRU which restricted potential output growth. Therefore, any policy aiming to increase economic growth, while neglecting structural reforms will prove to be unsustainable.
\end{abstract}

Keywords: Production function; Factor productivity; NAIRU; Potential output

\section{INTRODUCTION}

The output gap constitutes the deviation of actual output from potential output, whilst the potential output represents the best composite indicator of an economy and of its scope to generate sustainable, non-inflationary, output growth. The output gap points on the slack of the economy to achieve its potential growth level. It provides therefore, a measure of relative supply and demand pressures in an economy at a precise time enclosing useful short-term information for the formulation of economic policy which aims to control inflation.

However, Okun (1962) analyzing the unemployment in the United States from 1920 to 1940, demonstrated an inverse linear relation between the gap in the unemployment rate to its natural rate on one hand and the gap in the output to its potential level on the other hand. This relation termed the "GAP version" states that for every $1 \%$ increase in the unemployment rate, a country's GDP will be roughly an additional $2 \%$ lower than its potential GDP. Therefore, estimating potential output constitutes a crucial part of the practice for assessing the cyclical position of the economy and its productive capacity.

Estimating the output gap is far to be a simple task since potential growth is not directly observable. Furthermore, the concept of Potential output significance varies with the variation of time horizon. The fact that actual GDP is subject to significant historical / forecast revisions makes the estimation of potential output more difficult. Notwithstanding given the importance of the concept and the difficulty to hold strict definition for it, a wide variety of methods are used in estimation exercises. These methods are classified into two main groups: Pure statistical methods and econometric methods.

An economic based method permits the examination of the underlying economic factors which are driving any observed changes in the potential output indicator. More precisely, the estimation of potential labor as required by this method https://doi.org/10.30585/icabml-cp.v2i1.205

(C) 2018 the Authors. Production and hosting by Avicenna FZ LLC. on behalf of Dubai Business School, University of Dubai - United Arab Emirates. This is an open access article under the CC BY-NC license. 
allows the calculation of a non-accelerating inflation rate of unemployment (NAIRU) which is a benchmark for assessing the degree of spare capacity and inflationary pressures in the labor market. The difference between the unemployment rate and the NAIRU - or the 'unemployment gap' - is therefore an important input into the forecasts for wage growth and inflation. Consequently, this method gives the opportunity of establishing a meaningful link between policy reform measures with actual outcomes.

The aim of the paper is to review some of the methods employed in estimating potential output and to obtain a new estimate of potential output (and hence the output gap) for the Lebanese economy. Therefore, an estimation of structured production function is performed to derive the potential output. The underlying factors driving changes in potential output are examined. The rest of the paper is organized as follows. Section 2 clarify the concept of potential output. Section 3 provides some background on the different methods used to estimate potential output, Section 4 outlines the methodology employed in this paper to estimate potential output and generate output gap, Section 5 provides estimation results of Lebanese potential output and Section 6 concludes.

\section{THE POTENTIAL OUTPUT CONCEPT AND OVERVIEW OF ESTIMATION METHODS}

\subsection{The potential output concept}

The potential output or the long run trend represents the level of production when the production factors are fully utilized. However, the concept is appreciated differently when employed in a short, medium- or long-term perspective:

- In the short run, the physical productive capacity of an economy is considered as quasi fixed. However, its comparison with the effective / actual output changes (i.e. in output gap analysis) shows by how much total demand can increase during that short period without making supply constraints and inflationary pressures

- In the medium term, the concept of potential output explains that the improvement of domestic demand when it is maintained by a robust growth in the amount of productive investment may endogenously generate the productive output capacity needed for its own support. The latter is even more likely to happen within an environment of high profitability supported by an adequate wage progress related to labor productivity.

- Lastly, in the long run, the potential output is connected to the future evolution of the notion of total factor productivity and to the expected growth rate of potential labor.

The method to estimate the potential output is also related to the term perspective of the output concept. For the short run the pure statistical method is the one adopted by economists while, economic method is more suitable for medium and long run analysis since, over the medium to long run, a closer relationship between a specific variable and its underlying fundamentals is expected.

Nonetheless, conducting either type of analysis requires several arbitrary choices, either at the level of parameters (in statistical methods) or in the theoretical approach and choice of specifications, data and techniques of estimation (in econometric work). Estimation results are often quite sensitive to the specific method employed and are in general not robust across methodologies.

\section{2 Overview of Methods and empirical Literature}

Sustained long run growth (trend) and fluctuations around the growth path (cycle) are the features that characterize most of macroeconomic time series. Estimation the potential output involves the composition of the real GDP time series into trend and cyclical components. The empirical literature shows two main group of methodology to estimate the potential output: the statistical approach and the economic variables approach. Both have associated advantages and disadvantages, with the final choice of approach determined by the type of analysis and the purpose of the research.

\subsubsection{Statistical Approaches}

Statistical method uses the time series database to find the turning point on time series data. It provides a mechanical way of obtaining estimates for potential output without resorting to economic arguments or the need to consider the 
underlying fundamentals driving their evolution. This approach may serve for short run considerations as in the long run, economic variables are subject to numerous, shocks which often result in a disconnect between the variable of interest and its underlying fundamentals.

Three categories of statistical method to generate the potential output defined as the long-term trend of the actual output: linear trend method, Segmented trend method, and Filters method.

\subsubsection{Linear Trend Method:}

The simplest statistical detrending technique is the linear time trend method. It is builds on the assumption that a series can be decomposed into a deterministic trend component and a cyclical component. Equation (1) represents the trend-cycle decomposition of real GDP time series $x_{t}$ :

$$
x_{t}=g_{t}+c_{t}+\varepsilon_{t}
$$

Where, $g_{t}$ represents the growth (the trend component of $x_{t}$ ), and $c_{t}$ is the cyclical component of $x_{t}$ for $\mathrm{t}=1, \ldots, \mathrm{t}$, and $\varepsilon_{t}$ represents the error term.

It is assumed that the trend and cycle are fully uncorrelated. It is also, largely recognized that the trend component is subject to stochastic shocks. Consequently, if deterministic trends are used to calculate potential output, there is a risk that the stochastic trend element may not be fully removed.

\subsubsection{The Segmented Trend Method}

The Segmented trend method is derived from the linear trend method and is used by US National Bureau of Economic research (NBER) to estimate potential output. This method assumes that potential GDP is experiencing phases of acceleration and deceleration and search the "break up dates" which reflect changes in the evolution of the potential GDP by resolving the following equation:

$$
x_{t}=\gamma+\mu \tau+\sum \quad \mu_{r} \tau r+\varepsilon_{t}
$$

Where, $x_{t}$ represents the log of real GDP and $r$ the "break up date" in the trend. The value of $\tau r$ is a time variable: $\tau r=$ 0 if $\tau<r$ while $\tau r=\tau-r$ if $\tau>r$. The stationarity of the GDP time series is a pre-condition to not obtain misleading results in identifying business cycles.

The segmented method has the advantage to mak the trend business cycle components less sensitive to the abnormal values that may exist in the different sub periods. However, the arbitrary choice of the "break up dates" for the potential GDP lowers the accuracy of this method.

\subsubsection{The Hodrick Prescott (HP) filter}

The Hodrick Prescott (1980) filter is dedicated for business cycle and trend estimation. Singleton (1988) and Cogley and Nason (1995) used this method to decompose and extract business cycle.

As with the linear time trend method, the HP-filter assumes that time series' can be decomposed into a trend component and cyclical component. The properties and shortcomings of this filter are well documented in (Harvey and Jaeger (1993); St Amant and Van Norden (1997); Cerra and Saxena (2000), McMorrow and Roeger (2001) and Mise, Kim and Newbold (2003)). HP filter is constructed using penalty-function method. Moving smoothly over time, this filter optimally extracts the stochastic trend (unit root). It is built as a response to the minimization problem of variability in the cyclical component subject to a penalty for the smoothness of the trend component or the variation in the second difference. To calculate the smoothness of cyclical component, the sum of squares of its second difference is considered. Consequently, to isolate the cycle component, the HP-Filter resolve the following minimization problem:

$$
\operatorname{Min}\left[\sum_{t=1}^{T} \quad(x t-g t)^{2}+\lambda \sum_{t=1}^{T} \quad((g t+1-g t)-(g t-g-1))^{2}\right]
$$

where $x_{t}$ represents the real GDP time series, $g_{t}$ represents the growth component (potential GDP or trend) of $x_{t}$, and $c_{t}$ is the cyclical component of $x_{t}$ for $\mathrm{t}=1, \ldots, \mathrm{t}$. 
The first term of equation (2) measures the fitness of the time series' and the second term measures its smoothness. A conflict may exist between "goodness of fit" and "smoothness". A trade-off parameter $\lambda^{1}$ is called to resolve this issue, if lambda is 0 , the trend component becomes equivalent to the original series while diverges to infinity, the trend component approaches a linear trend.

The business cycles $c_{t}$ is however, the difference between the GDP time series $x_{t}$ and the growth component $g_{t}$ for $t=$ $1, \ldots, t$ :

$$
c_{t}=x_{t}-g_{t}
$$

The main disadvantage of the HP filter is that it generates a biased trend estimation at the end of the sample. Thus, the potential GDP estimation at the end of the period may be unstable and subject to several updates and revisions when new data on the observed GDP are available.

Although the severe discussions and heavy criticism (Cogley and Nason 1995, King and Rebelo 1993, Canova 1994), the HP filter stood remarkably. the filter has some useful characteristics in that it allows for stochastic shocks to the trend component, it is relatively simple, transparent and requires minimal value judgement. It is easily reproduced and is highly comparable across countries.

An expansion of the HP-filter is the multivariate HP-filter. This filter adds to the HP filter at least one additional source of information to enlarge the information set used in estimating the unobserved potential output (see Laxton and Tetlow, 1992; Butler, 1996). Thus, the residuals from macroeconomic relationships that include the output gap should be considered as supplementary conditioning variables in estimating trend output. An alternative, albeit somewhat more complex, method to the HP filtering technique is the Kalman filter technique.

\subsubsection{The Kalman filter technique}

The Kalman filter also known as quadratic linear estimation is a computational algorithm providing efficient means to estimate the state space approach of a process under a Gaussian environment. After the publishing of Kalman's (1960) paper in the Journal of Basic Engineering, the usage of this filter has spread into tremendously broad range of areas, such as chemistry, nuclear medicine, finance, econometrics, statistics. Nonetheless, the Kalman filter is widely used in economics literature: Burmeister and Wall (1982) used the filter to model rational expectations and hyperinflation in Germany. Hodrick and Prescott (1997) in modeling the US business cycles used the Kalman filter to develop their own HP filter. Chen (2001) applied Kalman filter to compute the inflation and the term structure of real interest rates under the expectations hypothesis.

The filter supports estimation in several aspects for past, present and future events (Welch and Bishop, 2004). Its technique, or unobserved components approach as pioneered, amongst others by Harvey (1992) assumes that macroeconomic time series are formed from distinct trend, cyclical and stochastic components. Thus, the decomposition of individual series (such as GDP) into trend and cycle components, in a univariate framework, in addition of imposing enough restrictions on the trend and cycle and considering assumptions on the functional form of these components and the structure of the error processes, allow components to be recovered from the observed series. A multivariate extension which allows for additional information to assist the decomposition process is also possible. The main attraction of the unobserved components approach lies in the fact that it offers a wide range of choices concerning the specification of the trend and cycle. It also allows for the possibility of using other empirical economic information for extracting cyclical components. However, this approach requires considerable programming and results are often subtle to the initial choice of parameter values.

\subsubsection{Econometric Methods}

Economic method attempts to isolate the effects of structural versus cyclical influences on output using economic theory. Econometric techniques for estimating potential output involve, the structural VAR (SVAR) approach, the estimation of

\footnotetext{
${ }^{1}$ The height of the value $\lambda$ depends on the frequency of the data. In the literature the following values are suggested: 100 for yearly data, 1600 for quarterly data and 14400 for monthly data.
} 
trend output based on dynamic stochastic general equilibrium (DSGE) models and the production function approach. The production function approach is discussed in detail in following sections as this is the approach applied in this paper.

\subsubsection{SVAR method}

Structural methods that are based on economic theories, are divided into autoregressive vector model, called also the VAR models and estimation of neoclassical production function. Where, the VAR model, explained by Granger (1969) and Sims (1980), replaces classical econometric model of several structural equations which involve simultaneity endogenous and exogenous variables. While the production function links the GDP to the gross fixed capital formation, employment rate and total factor productivity.

The general philosophy underlying the SVAR approach to estimate potential output reposes on the theoretical idea that demand shocks are transitory, while supply shocks have permanent effects on output.

Blanchard and Quah (1989) using economic theory developed an SVR model. They imposed restrictions on the traditional Keynesian and neoclassical synthesis which identifies potential output with aggregate supply capacity and cyclical fluctuations with changes in aggregate demand and, suggest that imposing various long run restrictions on a system in output and other relevant variables (such as the real exchange rate and/or inflation), structural supply disturbances can be recovered. Thus, the path of potential output can be derived using the resulting vector of supply shocks.

One of the advantages of the SVAR approach is that it relies on clear theoretical foundations and does not impose undue restrictions on the short-run dynamics of potential output. An obvious drawback is that the chosen identifying restrictions may not be applicable in all circumstances.

\subsubsection{The dynamic stochastic general equilibrium models}

The DSGE models have recently been utilized to generate more robust estimates of potential output. These models are based on microeconomic foundations which emphasize that all agents are rational and make decisions based on intertemporal optimization under uncertainty. In other terms, economic agents' decisions today depend on their expectations on future uncertain outcomes. Julliard et al (2006) estimate a DSGE model for the US and use the forecasts of the model to generate robust end-of-sample estimates of the output gap smoothed by HP-filter. Smets and Wouters (2003) developed a DSGE model with sticky wages and prices for the euro zone using Bayesian estimation techniques. Their model incorporates a variable capital utilization rate while findings prove a considerable degree of price stickiness in the euro zone. Christiano, Eichenbaum and Evans (2005), used a DSGE model along with staggered wages and price contracts to investigate the evidence of output persistence and inflation inertia that occurs under a mix of frictions.

However, measures of potential output obtained from DSGE models are dependent on the underlying characterization of the economy employed in the specific modelling exercise. Changes in the underlying characterization can lead to substantially different estimates of potential output.

\subsubsection{The production function method}

The Neoclassical production function is initially developed by Wicksell (1851-1926). In 1928 Cobb and Douglas used the production function to model the American economy's growth. They presented the production output as a combination's result of an amount of capital invested and an amount of Labor involved.

A generalization of the Cobb-Douglas production function termed constant elasticity of substitution function (CES) is developed by Arrow and al (1961). The central parameter of the CES production function is the measure of the elasticity of substitution's force between Labor and Capital. Though, the CES production function exhibits many limitations. On one hand, integrating more than two inputs makes the estimation of substitution more complex. On the other hand, the CES faces problem with the aggregation of the production function. It is an adequate function to explain the production of the firm but not the aggregate production function. Moreover, the technological progress lowers the possibility to identify the production function.

However, the optimization objective may be realized by two choices of optimal combination: minimizing the cost for a given output leading to maximizing the productivity. Thus, the potential output shows the capacity of the economy. Where the capacity represents the maximum output using fully and efficiently the available inputs adding the technology variable. 
The production function (PF) method is based on the Solow $(1956,1957)$ economic growth model where the exogenous technological evolution, not explained by this model, is the only driver of the output growth, once the economy reaches its steady state. In other terms, technological progress represents the only path to growth when the combination of per capita GDP and per capita Capital remains at rest. The relation between output in one hand and inputs affected exogenously by the total factor productivity is represented by equation (5):

$$
Y_{t}=A_{t} K_{t}^{a} L_{t}^{b}
$$

Where: $Y_{t}$ is the total production in year $\mathrm{t}, L_{t}^{a}$ and $K_{t}^{b}$ are respectively the Labor and the capital input in year $\mathrm{t} . A_{t}$ is the total factor productivity which represents how intensely and efficiently the Capital and Labor are exploited in the production. $a$ and $\mathrm{b}$ represent the output elasticities of capital and labor respectively. Assuming constant return to scale $(a+b=1)$, the Cobb-Douglass production function (Equation 5$)$ is transformed in equation (6):

$$
Y_{t}=A_{t} K_{t}^{a} L_{t}^{1-a}
$$

\section{Research Objective:}

a) To compare the effect of macroeconomic variables, i.e. Gross Domestic Product, Inflation and Interest rate on the profitability of Pakistan Banking Sector under democratic and dictatorship regime.

b) To compare the effect of financial indicators, i.e. Size of the bank, liquidity and Capital adequacy on profitability of Pakistan Banking Sector under democratic and dictatorship regime.

\section{Research Hypotheses:}

Ho: Macroeconomic variables, i.e. Gross Domestic Product, Inflation and Interest have no impact on profitability of Pakistan Banking Sector under democratic and dictatorship regime.

Ho: Financial variables, i.e. Inflation, Interest rate and Liquidity have no impact on profitability of Pakistan Banking Sector under democratic and dictatorship regime..

\section{THE CHOICE OF METHOD}

All the presented methods have "pros" and "cons" and none can unequivocally be declared better than the alternatives in all cases. Therefore, what matters is to implement a method adapted to the research objective, with well-defined limits. On other terms, the choice of approach is determined by the type of analysis and the purpose of the research.

This research adopts the production function method to estimate the potential output and identify output gap. Since this technique allows for the examination of the underlying economic factors driving changes in potential output. Thus, it allows to make forecasts, or at least to build scenarios, of possible future growth prospects by making explicit assumptions on the future evolution of demographic, institutional and technological trends. In addition, the advantage of using an economic estimation method is that it can highlight the close relationship between the potential output and NAIRU concept, given that the (PF) approach requires estimates to be provided of NAIRU.

On the other hand, another strength of the production function approach is the reliability of the obtained estimates at the sample end points. However, this approach has the disadvantage, that it requires assumptions on the functional form of the production technology, returns to scale, trends the total factor productivity (TFP) and the representative utilization of production factors.

\section{THE CALCULATION OF POTENTIAL OUTPUT PROCESS AND DATA SOURCES}

\subsection{The calculation process}

The production function explains that potential GDP is represented by a combination of factor inputs, multiplied by the technological level or total factor productivity (TFP) (equation 5). The parameters of the production function essentially determine the output elasticities of the individual inputs, with the capital stock computed by the perpetual inventory 
method. However, estimating potential output amounts to remove the cyclical components of the individual production factors but the capital stock, since the latter is considered as fully utilized. Thus, to estimate potential output this research proceeds in two steps:

-The first step is dedicated to the calculation of Labor and capital elasticities by estimating equation (6).

-The second step is dedicated to the Potential Output $\left(\mathrm{Y}^{*}\right)$ estimation. The potential output is modeled by equation 7 derived from equation (6):

$$
Y_{t}^{*}=A^{*}\left(K_{t}^{a}\right)^{*}\left(L_{t}^{1-a}\right)^{*}
$$

Where $A^{*}$ is the potential TPF derived by the HP filter while the TPF series is being calculated as residual relatively to equation (6). $\mathrm{K}^{*}$ and $\mathrm{L}^{*}$ are the potential capital and potential labor respectively and a, the capital elasticity while 1 -a is the labor elasticity.

The potential output is defined as the maximum level of output consistent with stable inflation. This implies that the actual labor input used in the estimated production function should be adjusted for the gap between actual unemployment and the estimated non-accelerating inflation rate of unemployment (NAIRU).

\section{Measuring Potential output using a production function approach}

\section{First steep: Estimation of equation (5)}

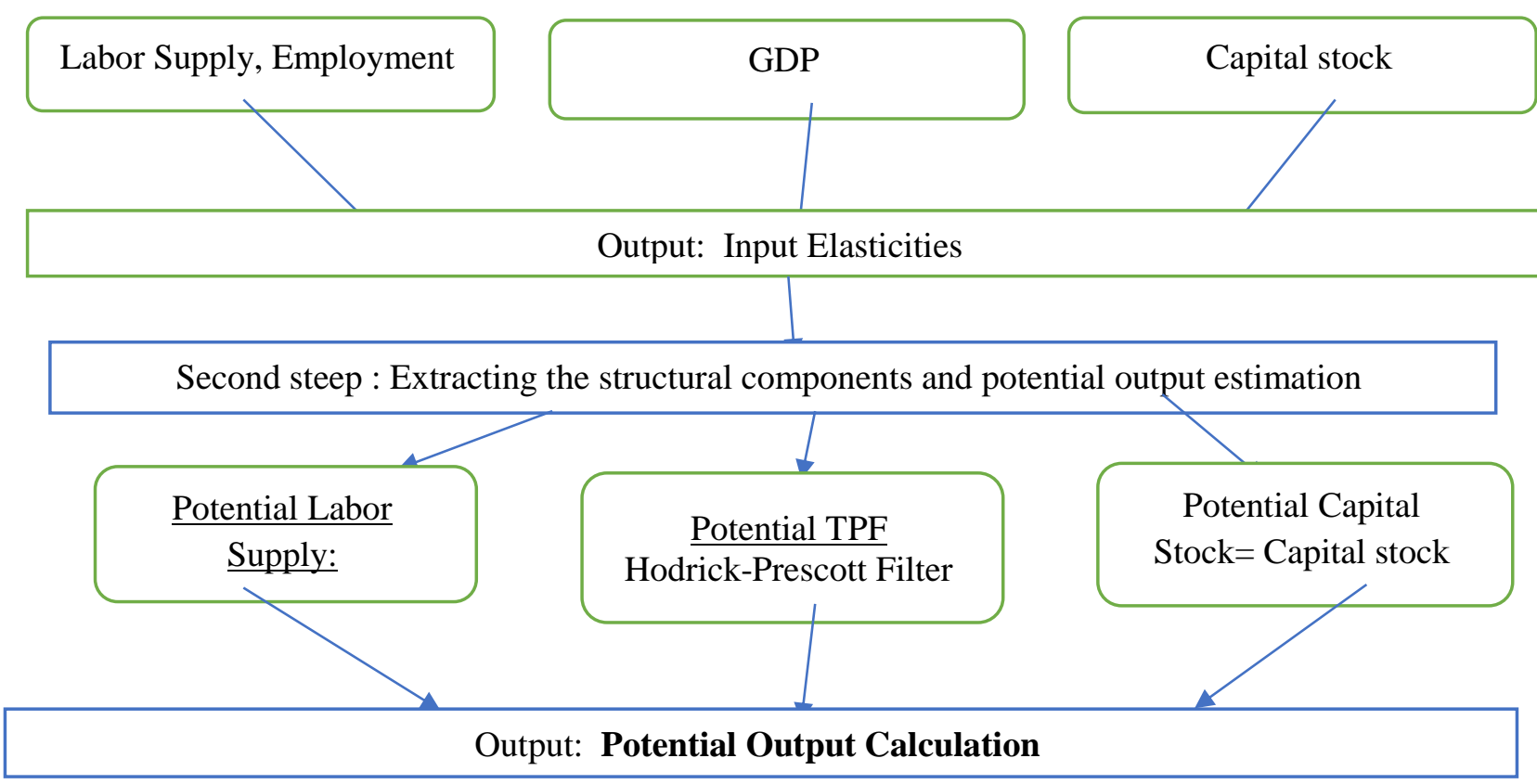

Yearly time series data for GDP, Capital, Labor, covering the period 1998-2015, are collected from the WORLD BANK's (World Development Indicators Database (WDI)). While, the capital stock is calculated by the Perpetual Inventory Method.

For the NAIRU calculations, the needed unemployment and inflation time series covering the same period are also collected from WDI on yearly basis. However, data related to institutionalized Population (prisoners and military) are collected as yearly secondary data from various reports. The yearly time series are then converted into quarterly time series using the Chow and Lin solution².

2 The Chow and Lin solution (1971) approach to disaggregate annual time series into quarterly levels is employed for being widely used in The National Statistical Institutes. This method provides coherent and natural solution to the 
Finally, the quarterly money supply time series is collected from Lebanese Centrale Banque while the oil price is collected from the U.S. Energy Information Administration (EIA). All series are considered in Log and all tests are executed using Eviews software.

\section{ESTIMATING POTENTIAL OUTPUT}

Potential output is a function of potential TPF, potential capital and potential Labor following equation. As detailed in paragraph 5 , the estimation of potential output is reached after executing the first step explained in paragraph 5.1 and the second steep in paragraph 5.2.

\subsection{Capital stock formation and elasticities of labor and Capital}

\subsubsection{Determination of Capital stock formation}

The current PF method takes the total capital stock into account. In terms of the measurement of the capital stock, the basic approach of perpetual inventory method is used. The corner stone of this method is the interpretation of the capital stock as an inventory. Thus, when a new investment flow is added to the economy's inventory, the Capital formation (Investments) increases.

Since the capital stock is assumed not to be subject to cyclical fluctuations, any (increase in) investment directly enters the production function and is translated into (an increase of) potential output. In addition, since all types of capital goods, from machinery to various forms of residential and non-residential buildings / infrastructure, are considered together as one aggregate, consequently we are implicitly calculating the average productivity of the capital stock as a whole rather than the productivity.

The capital stock of each period is, measured by the previous period stock (net of depreciation) augmented with new investment flows. However, the investment provides its maximum quantity of services at the present period while the investment value depreciates with the time progress. The depreciation rate of investment is the amount by which the capital stock falls per period. Assuming geometric depreciation at a constant rate $\delta$, the net capital stock at the beginning of period $t, K_{t}$, is therefore a function of the net capital stock at the beginning of the previous period $t-1,\left(K_{t-1}\right)$, and gross new investment flow, $I_{t}$, equation (8) represents the capital stock formation .

$$
K_{t}=(1-\delta) K_{t-1}+I_{t}
$$

with Initial capital stock $K_{0}=\frac{I_{0}}{(\delta+i)}$

Where $I_{0}$ is the initial investment expenditure, and $i$ the investment's average logarithmic growth rate, calculated for period QI-1998 to QIV-2015, i= 0.77\%. However, the application of equation (7) assumes a physical capital depreciation rate of 0.05 . This assumption is consistent with past research on MENAP made by the IMF $^{3}$, and additional furnished data from Knoema (Penn World Table 9.0) regarding the average depreciation rate of the capital stock in Lebanon ${ }^{4}$

\subsubsection{Capital and Labor Elasticities calculation}

Dividing each side of equation 7 by $L$ and considering the stochastic behavior of the time series gives the model 8 :

$$
y_{t}=A k_{t}^{a} e^{u}
$$

Where, $Y_{t}=Y_{t} / L_{t}$ and $k_{t}=K_{t} / L_{t}, u$ is the error term and $a$ the capital elasticity

\footnotetext{
interpolation method, since its procedure is theoretically practical. was developed firstly by Chow and Lin in 1971, than evolved by Fernandez in 1981 and Litterman in 1983

3 (IMF 2012, IMF 2013b, IMF 2013d, and the Total Economy Database (TED) from Chen and others 2010) as well as on oil importers (IMF 2014, TED from Chen and others 2010, and Gollin 2002) which assume physical capital depreciation rate from 0.05 to 0.15 .

${ }^{4}$ https://knoema.com/PWT2015/penn-world-table-9-0?tsld=1027870/ https://knoema.com/search?query=capital\%20depreciation
} 
The preference of method for estimating the equation (8) depends on the integration level of individual time series (yt) and (kt). This integration level is investigated by three tests: Augmented Dickey Fuller (ADF), Philip Peron (PP) and Kwiatkowski-Phillips-Schmidt-Shin (KPSS) tests.

\subsubsection{STATIONARY TESTS RESULTS}

Table 2 shows the ADF, PP and KPSS test results for the two series $\mathrm{y}_{\mathrm{t}}$ and $\mathrm{k}_{\mathrm{t}}$. According to the three tests results the two individual time series $\mathrm{y}_{\mathrm{t}}$ and $\mathrm{k}_{\mathrm{t}}$ are stationary in level for $1 \%$ level of confidence. In other terms both time series, $\mathrm{y}_{\mathrm{t}}$ and $k_{t}$ are $I(0)$.

Table 2: Unit test results for individual quarterly time series of output per Labour (y) and capital by Labour (k) through the period 1998 to 2015

\begin{tabular}{lcc}
\hline the period 1998 to 2015 & $y$ & $\mathrm{k}$ \\
\hline ADF test & $2.015764^{* * *}$ & $0.117458^{* * *}$ \\
t-statistic in levels & & \\
\hline Phillips-Perron test & $0.553548^{* * *}$ & $-0.737614^{* * *}$ \\
Adj t statistic in level & & \\
\hline KPSS test & $0.179858^{* * *}$ & $0.293545^{* * *}$
\end{tabular}

Note: $* * *$, and $* * *$ show the statistical significance at the $10 \%, 5 \%$, and $1 \%$ level of significance respectively

Source: Calculated by the author using EViews

\subsubsection{Estimation results}

Since the two individual time series are $\mathrm{I}(0)$, Ordinary least square method $(\mathrm{OLS})$ is carried out to estimate the linearized form of equation (8). Therefore, as shown by the regression results (equation (9)), the capital elasticity $a$ is 0.22 . Consequently, the Labor elasticity $=1-a=0.78$.

$$
\begin{aligned}
& \log _{t}=12.06817+0.22 \log k_{t} \\
& (0.0019) \quad(0.0000)
\end{aligned}
$$

With the number in parentheses indicate the parameters probabilities. Since theses probabilities are less than $5 \%$, the estimation regression indicates that both the constant and the capital are significant.

\subsection{Estimating potential TPF and potential inputs}

The second step of potential output estimation process includes the estimation of potential TPF as well as the estimation of potential capital and Labor. The potential capital stock is equal to the total existing stock of capital. However, depending on the assumption that, given the perpetual inventories rule, the capital stock is regarded as an indicator for the overall capacity of the economy (Denis et al., 2000). In other terms, the capital is assumed to be fully utilized. Thus, no justification to smooth this series in the production function approach. Consequently, this step calculates only potential TPF and potential Labor to proceed the computation of potential output.

\subsubsection{Estimating Total Factor Productivity}

The series related to the total factor productivity is not observable. Consequently, the total factor productivity term, which is the contribution of capital and Labor to actual real GDP, is obtained as a Solow Residual from equation (6): $A_{t}=$ $Y_{t} / L_{t}^{a} K_{t}^{1-a}$ Thus,

$$
\log \left(A_{t}\right)=\log \left(Y_{t}\right)-0.22 \log \left(L_{t}\right)-0.78 \log \left(K_{t}\right)
$$


Following Gradzewicz and Kolasa (2005), the HP filter is applied to smooth the original calculated series $(\lambda=1600$, for quarterly basis) and to approximate the trend of Total Factor productivity for the Lebanese economy (At*).

Figure 1 shows that the total factor productivity was approximatively stable during the period Q4/1997 -Q2/2005 to increase steadily after the fourth quarter of 2005 till the fourth quarter of 2010. Since the fourth quarter of the year 20011 the TPF continue to decrease indicating that the contributions of both capital and labor have increased substantially. However, growth theories advocate that GDP growth can generally be sustained over longer periods when based on technological progress and improvements in efficiency rather than factor accumulation. In other terms, the growth based on capital and labor accumulation as the Lebanese economy will face the problem of facing natural limits based on demographics and diminishing returns.

\section{Figure1: The quarterly TPF (A) and potential TPF (HPA) series from 1997 to 2015}

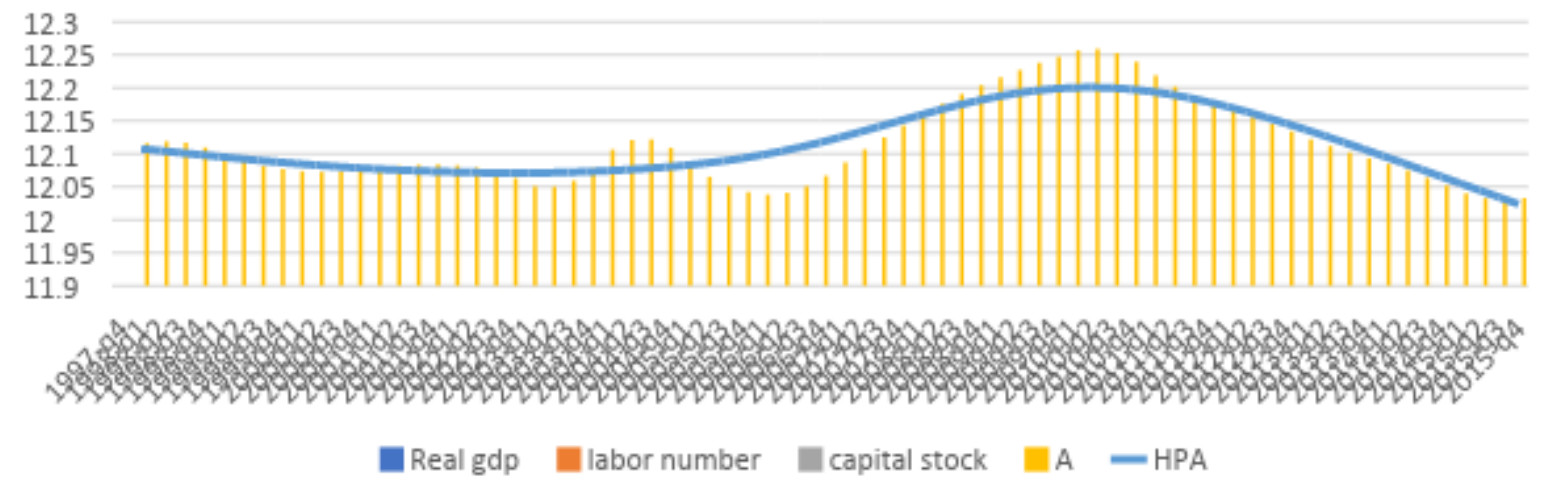

\subsubsection{Estimating Potential Employment}

Potential output is defined as the maximum level of output consistent with stable inflation. This implies that the actual labor input used in the estimated production function should be adjusted for the gap between actual unemployment and the estimated non-accelerating inflation rate of unemployment (NAIRU). To that end, potential employment is defined as follows:

$$
L_{t}^{*}=\operatorname{LFPR}_{t}^{*}\left(1-N A I R U_{t}\right)
$$

Where $L^{*}$ is the potential Labor and LFPR* is the potential Labor force participation rate. While LFPR= Labor force as defined by the international Labor Organization ${ }^{5}$ (ILO) divided by the Civilian Non-institutionalized Population . $^{6}$

\subsubsection{The theoretical background of the NAIRU}

The non-accelerating inflation rate of unemployment (NAIRU) is implicitly defined as the equilibrium point of a dynamic system of labor supply and labor demand equations. This equilibrium concept is linked to the Phillips curve bargaining model between inflation and unemployment. The lower the rate of unemployment, the higher the rate of inflation. In other terms it exists a tradeoff between unemployment and inflation. However empirical evidence falls to demonstrate a permanent unemployment-inflation tradeoff. The data for the period 1970 till 1980, in both Britain and the US do not fit the simple Philipps curve story. The Philipps curve is rather flat in the short run and quite vertical in the long run. Thus, the tradeoff between unemployment and inflation is only proved on the short run.

\footnotetext{
${ }^{5}$ The IOL defines the Labor force includes everyone aged between 15 and 64 .

${ }^{6}$ Civilian Non-institutionalized Population includes everyone who is 15 and plus but Institutional internees should be deducted like prisoners and mentally patients in hospitals, as well as those in military service.
} 
Freidman (1968) complete the missing piece of the puzzle in the Philips curve model by introducing the concept of expected or anticipated inflation. He explains that, workers and firms are concerned with the real wage value. Both parties are roughly willing to adjust the level of the nominal wage for any expected inflation over the contract's period. Consequently, unemployment depends not on the level of inflation but on the excess of inflation over what was expected. While the output is always at its full-employment level when both actual and expected inflation are equal.

Friedman clarifies the idea that given an average set of shocks, the natural rate of unemployment is the level of unemployment that the economy would tend to produce. Thus, a monetary policy action to stimulate economic activity and reduce the unemployment rate, turned to be ineffective whenever the unemployment rate is permanently inferior to the natural rate. The hypothesis of the long run natural rate of unemployment suggests that a permanent increase in price wages cannot be expected to reduce in the long run the unemployment rate but only a temporary decrease in unemployment as the economy will finally adjust to its natural rate. Thus, Since Friedman contributions, a consensus has emerged that with long run, there should be no long run trade-off between the rate of inflation and the rate of unemployment.

The rational behind the (NAIRU) concept developed by the New Keynesian economists, advocate of the imperfect competition model, is that the unemployment rate will always return to its equilibrium value, regardless the level of the long run inflation rate. The NAIRU or the rate of unemployment at the long run equilibrium is therefore, identical to the natural rate of unemployment concept formulated by the Monetarist (Friedman) and the Neo-Classical economists.

On the other hand, the NAIRU estimation allows Monetary authorities to determine the likely path of the inflation, and the actions that should be taken for price stability purpose. It is widely used by the US budget office to make budget projections and to subtract the potential GDP.

However, by the late of 1990s, (Staiger 1997, Stock and Watson 1999) report that the NAIRU is imprecisely estimated. (Gordon 1997; Cohen, Dickens and Posens; 2001Ball and Mankiw 2002) argue that NAIRU changes over time, rising problems for policy formation.

\subsubsection{NAIRU Estimation methodology}

The concept of NAIRU is difficult to quantify because it is not observable. However, numerous estimation methods can be used to measure this variable. These methods may be divided into three categories: the statistical method, the structural method and the reduced-form method.

In the statistical method, the actual unemployment rate is directly divided into cyclical and trend components, where the NAIRU is simply the trend component.

In the structural method, the NAIRU is derived as the equilibrium of a structural model of the aggregate wage and price setting behaviors, assuming that markets are in full or some partial equilibrium.

In the reduced-form method, the NAIRU is estimated, similarly to structural method, based on a behavioral equation explaining inflation, the Phillips curve model. This method is considered as a compromise between structural and statistical methods, and the most popular technique in recent studies because it is simple to apply. It requires embedding the unobserved variable, the NAIRU, in a standard Phillips-curve relation where inflation responds to the unemployment gap. This framework allows incorporation of various other explanatory variables such oil price and money supply growth, in the Phillips-curve relationship.

Unfortunately, the reduced-form method has, also, several disadvantages. The main disadvantage is that "the results may be sensitive to arbitrary choices in the model" (Szeto and Guy 2004). The parameter that is chosen arbitrary is the signal to noise ratio ${ }^{7}$. Stock and Watson (1988) have attempted to resolve this problem while estimating this ratio that has been applied to an unobserved components model of trend growth of per capita Gross Domestic Product in post-war U.S. economy.

The road map to estimate the NAIRU as follows: The NAIRU is calculated through two different methods: first method is a purely statistical method, the Hodrick Prescott filter where the extracted trend is the NAIRU. The second method is

\footnotetext{
7 The signal-to-noise ratio measures volatility or variance in the NAIRU relative to volatility or variance in inflation. For more explication, see the fourth section in this paper.
} 
the reduced form method where the Phillips model is regressed. However, relative to the Philips curve model, the NAIRU is calculated as time Invariant NAIRU and Time varying NAIRU. Two techniques are used to determine the Time varying NAIRU: the long-term and short-term shocks estimation and the unemployment GAP estimation.

\subsubsection{Philips curve model}

The Philips curve model is based on the Keynesian theory, reflecting the negative relation between unemployment and inflation. In other terms, the Philips curve model is a short run bargaining model represented by equation 11 .

$$
\pi=H-\rho U
$$

Where $\pi$ is the inflation, $U$ is the unemployment, $H$ is a constant and $\rho$ parameter $>0$.

However, Samuelson and Solow (1960) state that fundamental factors would cause the shift in the tradeoff over time. A consensus is developed between economists, that the unemployment rate will always return to its equilibrium value, regardless the level of the long run inflation rate. The NAIRU or the rate of unemployment at the long run equilibrium is therefore, identical to the natural rate of unemployment. As consequences, with $Z_{t}$ represents an external shock and $\varepsilon_{t}$ the error term, the bargaining Philips curve model is given by equation (12):

$$
\Delta \pi_{t}=\rho U_{t}-\rho U^{*}+Z_{t}+\varepsilon_{t}
$$

Where $\Delta \pi$ is the changes in inflation and $U^{*}$ is the natural rate of unemployment (NAIRU).

A range of research uses the form of the equation (12) to estimate the inflation with lags of inflation and unemployment are included differently in each study. While, different control variables are chosen to represent the supply shocks (See Gordon (1998) and Staiger, Stock and Watson (1997)). This research considers 2 supply shocks, the Money supply shocks and changes in oil price (crude oil WTI price). The Money supply is related to inflation via the Fisher formula (MV= PT with $M$, the money supply, $V$ the money velocity, $P$ the price level and $T$ the transaction during the period). The oil is an important input for all industry and is crucial for transportation. An increase in oil price is therefore causing an increase in the production cost and inflation as consequences.

On the other hand, Friedman (1968), stress the role of expected inflation in explaining the shifts in the inflationunemployment tradeoff curve. The short-run non-neutrality theory states that any increase in expected inflation is allied to an equal increase in actual inflation.

Thus, a revised version of the above equation (12) is proposed by equation 13 , where the inflation expectation play a central role to explain the shift in the inflation/unemployment tradeoff.

$$
\pi=\pi^{e}-\rho\left(U-U^{*}\right)
$$

With, $\pi^{e}$ represents the expected inflation, $U$ the unemployment rate, $U^{*}$ the natural rate of unemployment which represents the unemployment rate an economy should reach that in the long run an economy. It integrates both shifts resulting from expected inflation and the one of the tradeoff presented by the parameter $H$ in the previous equation, $Z_{t}$ the external schoks $\rho$ parameter and $\varepsilon_{t}$ the error term.

Thus, the rationality of expectations assumes that on the long run, the actual inflation should be equal to the average of expected inflation. Consecutively over the same long interval unemployment cannot deviate from the average natural rate.

Freidman (1977) explains that Entrepreneurs recognize before workers do, what is going to be the rate of inflation. Entrepreneurs find that hiring workers at a reduced real wage is interesting for them while workers believe that they are being employed at somewhat improved real wages since their perceptions regarding the inflation rate are lagging. Therefore, the equilibrium in the labor market is attained when same beliefs regarding the inflation rate are shared by both sets of agents, even if both beliefs were erroneous vis-a-vis the rate of inflation in prospect. In other terms, any deviations of real output and employment from their initial equilibrium levels, reveal information differentials between the two groups of agents in the model, workers and entrepreneurs. 
However, the natural rate can be changeable over time and its variations can be the main source of the unemploymentinflation tradeoff shift. Whereof, an amended version of the previous equation is proposed by the literature, where changes in inflation is modeled as per the following Phillips curve equation:

$$
\Delta \pi_{t}=\pi^{e}-\rho\left(U_{t}-U^{*}\right)+Z_{t}+\varepsilon_{t}
$$

The conventional approach to measure the inflation expectations, suggests that expected inflation is a weighted average of past inflation. Thus, assuming that, $\Delta \pi_{t}, \Delta \pi_{t-1}$ and $\Delta \pi_{t-2}$ represent current and lagged changes in the inflation rate, $Z_{t}$ an exogenous regressor and $\varepsilon_{t}$ an uncorrelated error term, equation (14) is transformed into the following equation:

$$
\Delta \pi_{t}=\gamma+\alpha(L) \Delta \pi_{t-1}+\delta(L) \Delta \pi_{t-2}+\rho(L)\left(U_{t}-U^{*}\right)+\beta(L) Z_{t}+\varepsilon_{t}
$$

With $\alpha(L), \delta(L), \rho(L)$ and $\beta(L)$ are polynomials in the lag operator of order $0,0,0$ and 0 , respectively. and $\varepsilon_{t}$ is a serially uncorrelated error term

Equation 15 describes the NAIRU Triangle model of Gordon's (1997) where inflation is determined by three factors: expectations, the pressure of demand as proxied by unemployment and supply factors. The demand side influences through the $\left(U_{t}-U^{*}\right)$, the supply side through the external shocks $Z_{t}$, and price rigidities via past changes of inflation rates $\Delta \pi_{t-1}, \Delta \pi_{t-2}$

Thus, the natural rate of unemployment $U^{*}$ which is the unemployment rate in the long run integrates both shifts resulting from expected inflation and the one of the tradeoff presented by the parameter $H$ in the equation 11 .

\subsubsection{Constant NAIRU estimation results}

Assuming that, the natural unemployment rate $\left(U^{*}\right)$ is constant over the period of the study and that the supply shocks are contemporaneously uncorrelated ${ }^{8}$ with it. The constant NAIRU is obtained by estimating the Philips curve model without including inflation expectation (equation (12)) and with including inflation expectation (equation 14). In both equation, two external shocks, M2 growth (dM) and oil price variations (dP), are considered as exogenous regressor. The two regressors are included in two equations separately to test which external shock affects the most the inflation rate in the Lebanese economy. Therefore, in total the 4 equations are regressed to estimate the unemployment coefficient $(\rho)$, then after the NAIRU $\left(U^{*}\right)$ is calculated as the ratio of the constant term $\left(\rho U^{*}\right)$ divided by the absolute value of the unemployment coefficient $(\rho)$. Stationary tests for individual time series are however required as prior tests.

\section{Stationary tests and results}

Three prior stationary tests are carried out. Table 2 presents the ADF, PP and KPSS test results for the three time series, unemployment $(\mathrm{U}), \mathrm{M} 2$ growth $(\mathrm{dM})$ and oil price variations (dP). These results indicate that, at $1 \%$ level of significance the two time series, $(\mathrm{dM})$ and $(\mathrm{dP})$ are stationary in level according to KPSS, PP and ADF tests. The time series (U) is stationary in level according to KPSS at $1 \%$ level of significance and at $10 \%$ level of significance for ADF and PP tests. Therefore, the three individual time series are integrated of order zero which justify the application of OLS method without facing a spurious regression.

Table3: Unit root test results for individual quarterly time series of unemeployment rate (U), M2 growth (dM) and crude oil price changes (dp) through the period 1998 to 2015

ADF test $U$ dM dP

\footnotetext{
${ }^{8}$ Lucas (1973), considered the nominal GDP as the independent variable and assumed that the supply shocks in the residual were not correlated with the nominal GDP. While Barro (1977), considered the money growth and proved that the supply shocks do not influence the money growth
} 


\begin{tabular}{|c|c|c|c|}
\hline $\begin{array}{l}\text { t-statistic in levels } \\
\text { t-statistic in first differences }\end{array}$ & $\begin{array}{l}-1.0406 *- \\
1.040630 * 2.015764 * * * \\
-3.8374 * * *\end{array}$ & $\begin{array}{l}-7.0856 * * * \\
-\end{array}$ & $-5.9289 * * *$ \\
\hline \multicolumn{4}{|l|}{ Phillips-Perron test } \\
\hline Adj t-statistic in level & - 1.185620* & $-7.1458 * * *$ & $-5.7337 * * *$ \\
\hline Adj t-statistic in first differences & $-4.033293 * * *$ & - & \\
\hline \multicolumn{4}{|l|}{ KPSS test } \\
\hline LM stat in level & $0.110618^{* * *}$ & $0.0699 * * *$ & $0.4057 * * *$ \\
\hline \multicolumn{4}{|c|}{$\begin{array}{l}\text { Note: } * * * \text {, and } * * * \text { show the statistical significance at the } 10 \%, 5 \% \text {, and } 1 \% \text { level of significance respectively } \\
\text { Source: Calculated by the author }\end{array}$} \\
\hline
\end{tabular}

Equation 16 represents the estimation results of Philips curve model without inflation expectation (equation 12 ) and M2 growth as external shock

$$
\begin{array}{ccc}
\Delta \pi & 18.7020-8.4558 U_{t}+18.50 d M_{t} \\
\text { (0.0003) } & \text { (0.0008) }
\end{array}
$$

The regression estimation results indicate that both the coefficient of the unemployment rate (Ut) and M2 growth (dMt) are both significant with a P-value equal to (0.0008) and (0.0008) respectively. Furthermore, the constant is significant with a P-value equal to (0.0003). The R-squared indicates that the chosen explanatory variables explain $27.68 \%$ of the inflation variation.

However, the estimation results reveal also that the constant $=\rho U^{*}=\mathbf{1 8 . 7 0 2 0}$, the unemployment coefficient $\rho=\mathbf{( -}$ 8.4558). Thus, $\left(-8.4558 U^{*}=18.7020\right.$ implying a constant NAIRU equal to 2.211 .

Equation 17 represents the estimation results of Philips curve model without inflation expectation (equation 12) and oil price variations(dp) as external shock

$$
\begin{array}{cl}
\Delta \pi= & 20.77-9.26 U_{t}+0.009 d P \\
\mathbf{( 0 . 0 0 0 2 )} & \text { (0.0008) }
\end{array}
$$

These results show that the unemployment rate $\left(U_{t}\right)$ and the constant term are both significant while the oil price variations $\mathrm{dP}$ is insignificant to explain the changes in inflation. The R-square is equivalent to $15.09 \%$ and the NAIRU from the constant term equal to 2.242 .

Thus, on quarterly basis, the change in money supply influences inflation as external shock but not the change in oil price.

\section{Philips curve model including the inflation expectations estimation results}

Considering that expected inflation is a weighted average of past inflation $\pi^{e}=a \Delta \pi_{t-1}+b \Delta \pi_{t-2}$, and substituting into equation 14 represent a Philips curve model including inflation expectation. Equation 18 and 19 show the estimation results of this model including and $\mathrm{M} 2$ growth and oil price variations respectively as external shocks.

$$
\begin{array}{ccccc}
\Delta \pi=1.90+1.69 \Delta \pi_{t-1}-0.82 \Delta \pi_{t-2}-0.79 U+0.50 Z_{t} \\
\mathbf{( 0 . 0 6 7 5 )}(\mathbf{0 . 0 0 0 0 )} \quad \mathbf{( 0 . 0 0 0 0 )} \quad \mathbf{( 0 . 1 6 6 7 )}(\mathbf{0 . 6 9 9 2 )} \\
\Delta \pi=1.82+1.69 \Delta \pi_{t-1}-0.82 \Delta \pi_{t-2}-0.75 U-0.0001 Z_{t} \\
\text { (0.0785) (0.0000) }
\end{array}
$$


After including the inflation expectations, considering money supply growth or oil price changes as external shock, all variables except the inflation autoregressive terms became insignificant to explain the inflation changes in the Lebanese economy. On other terms, inflation expectations are "often slow moving", which means that the effects of demand pressures or supply shocks get built into the inflation process only gradually. As results, the constant NAIRU is better estimated by the equation (12), without including inflation expectations, which is the reasonable scheme for quarterly data.

\subsubsection{Estimation of TIME-Varying NAIRU (TVNAIRU)}

The question regarding the assumption of a constant NAIRU, more precisely since the apparent fall in the US NAIRU in the late 1990's. Consequently, a large literature grows to estimate the path of time-varying NAIRU.

The wide empirical literature analyzing the path of the TVNAIRU is based on two characteristics: the first characteristic admits that the movements in the natural rate of unemployment are illustrated by long-term shifts in the Phillips curve relation, while the second characteristic explains that, the short-run fluctuations are captured by the external supply side shocks.

The TVNAIRU Computes the long term and short term shifts in inflation-unemployment tradeoff. It relies on the standard "triangle model" approach that includes various measures of supply and demand shocks in the specification of the Phillips curve.

Considering equation 15 taking into consideration the long-term and the short-term shocks generate the following equation.

$$
\Delta \pi_{t}=\Delta \pi^{e}{ }_{t-1}-\Delta \pi^{e}{ }_{t-2}+\rho U^{*}-\rho U+Z_{t}+\varepsilon_{t}
$$

Where $\Delta \pi_{t}, \Delta \pi_{t-1}^{e}$ and $\Delta \pi^{e}{ }_{t-2}$ represent current and lagged changes in the inflation rate, $Z_{t}$ an exogenous regressor, $\mathrm{U}^{*}$ the NAIRU and $\varepsilon_{t}$ the error term.

Thus,

$$
U^{*}+\frac{z_{t}}{\rho}=U+\frac{\Delta \pi}{\rho}-\Delta \pi_{-1}^{e}+\Delta \pi_{-2}^{e}
$$

$\left(U^{*}+\frac{z_{t}}{\rho}\right)$ represents the sum of two kinds of shocks: the long-term trend represented by the NAIRU ( $\left.U^{*}\right)$ and the shortterm shocks represented by the external supply side shocks $\frac{Z_{t}}{\rho}$.

The calculation of the right-hand side of the equation $21:\left(U+\frac{\Delta \pi}{\rho}-\frac{\Delta \pi^{e}-1}{\rho}+\frac{\Delta \pi^{e}-2}{\rho}\right)$ allows to estimate the long term and short term shocks: $U^{*}+\frac{z_{t}}{\rho}$. The application of HP filter extracts the NAIRU $\left(U^{*}\right)$ from $U^{*}+\frac{z_{t}}{\rho}$.

However, the elasticity of unemployment $(\rho)$ is estimated as $=8.4558$. This elasticity value corresponds to the disinflation cost conventional wisdom: if the inflation rate decreases by $1 \%$ point, then an extra $\frac{1}{\rho}=\frac{1}{8.455822}=$ 0.12 point-quarterly (equivalent to $0.47 \%$ yearly) of unemployment is produced. On the other hand, depending on the data periodicity, the HP smoothing parameter is chosen equal to 1600.

Figure (2) shows the estimation of the Lebanese economy over the last 68 quarters (from 1998 to 2015). The solid line gives the values of $U^{*}+\frac{Z_{t}}{\rho}$, this represents the sum of long-term and transitory shifts in the inflation-unemployment tradeoff. The vertical lines give the results of HP filter applied on the unemployment time series. The smoothed series tells that the NAIRU has followed a hump-shaped path: it trended up from the first quarter 1998 until about the fourth quarter 2003, then peaked (the higher NAIRU is registered on the first quarter of 2003, for the value of 8.9) and has declined since then till reaching its lowest level (6.3) in q4-2014. 
Starting the fourth quarter of 1998 till 2000 a favorable shift in the Phillips curve has occurred, but these were sometimes interpreted as transitory supply shocks - that is, decreases in $U^{*}+\frac{Z_{t}}{\rho}$ were interpreted as movements in $\frac{Z_{t}}{\rho}$ rather than $U^{*}$. This interpretation was supported by direct evidence of favorable shocks during this period, such as, the adoption of fixed exchange rate regime, which reduced import prices and decreases the inflation as consequences. Furthermore, this period was characterized as the reconstruction period with execution of infrastructure project in transportation and telecommunications.

The estimated NAWRU is presented in Figure 2 along with the corresponding HP-filtered series. The sinusoidal curves correspond to the long term and short term shifts. these shifts represent the inflation-unemployment tradeoff. The path of the smoothed NAIRU can be described as hump-shaped curve. It trended up from q4-1998 till q2-2003 to decline and reach its lowest level in q4-2015.

From Q3 1998 to Q3 2000 the estimated NAIRU moves over it corresponding HP filter to fall under the smoothed value till Q12006. The failing estimated NAIRU was initially obscured by the run-up of actual unemployment after the political disturbance in 2005 and the Israeli's attack in 2006. Yet the period after 2005 did not see additional favorable shocks, and indeed, import prices moved up after the international financial crises in 2007. However, the moderate increase in the estimated NAIRU after 2013 may be caused by the political disturbances in Syria and the huge number of refugees to Lebanon increasing the available worker numbers. These circumstances generate an increase in Lebanese unemployment.

Figure 2: NAIRU estimation by HP filter (HPU) and through long-term and transitory shifts (LT+ST)

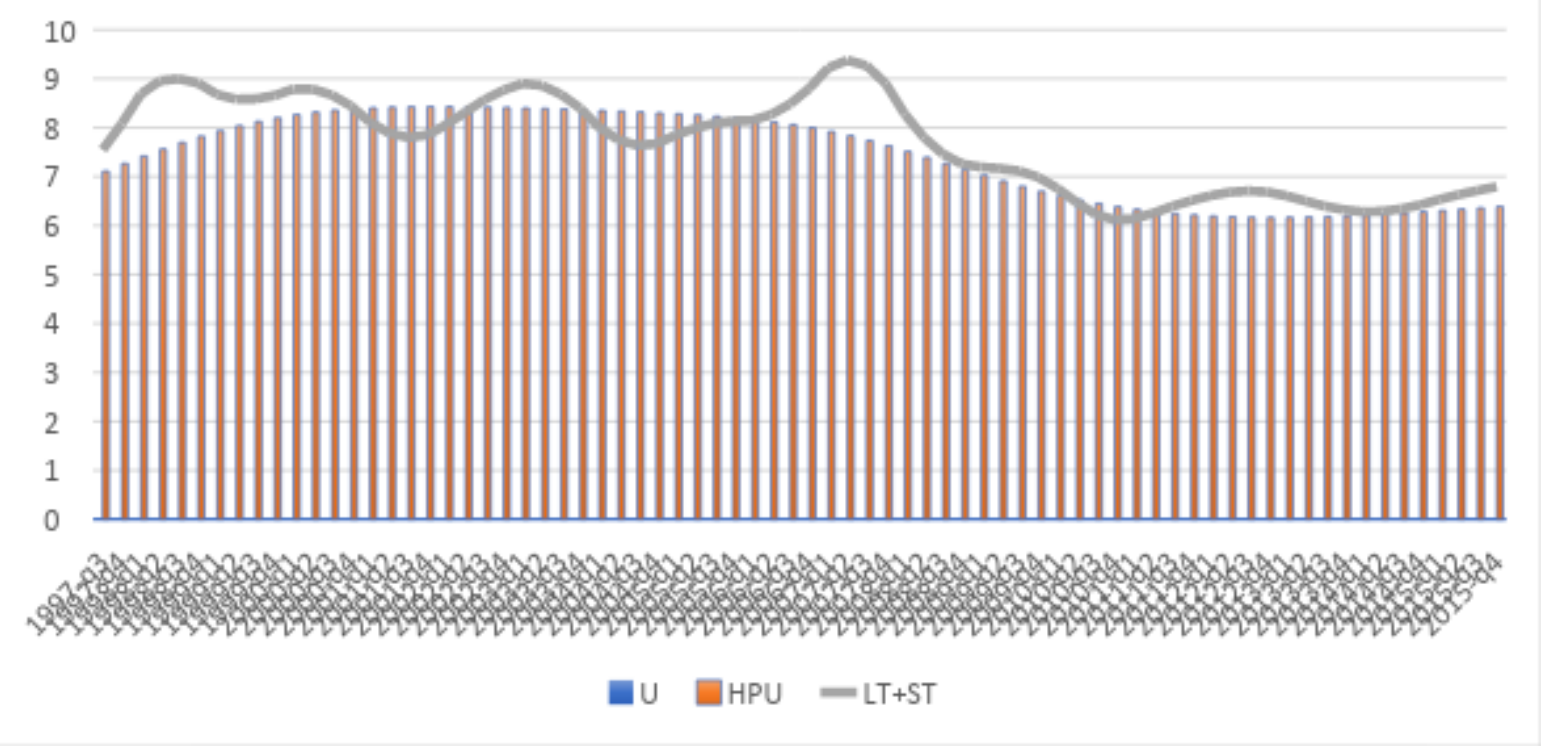

\section{Source: Author calculation}

\subsubsection{The unemployment Gap estimation}

The unemployment gap $\left(G_{t}\right)$ represents the difference between the unemployment rate $U_{t}$ and the natural rate of unemployment $U^{*}$.

$$
G_{t}=U_{t}-U^{*}
$$

Where, equation 22 helps to decompose the unemployment rate between a stochastic trend component $U^{*}$ and the cycle component $G_{t}:\left(U_{t}=U^{*}+G_{t}\right)$.

In the Philips curve model (equation15), the unemployment gap drives the deviations of inflation and wages growth from long-term inflation expectations. Thus The $G_{t}$ reflects by how much the deviation of the unemployment from its natural rate can influence or helps to predict the inflation rate. 
However, the cyclical component or the unemployment GAP modeled as a stationary second order autoregressive model gives the following equation:

$$
G_{t}=\emptyset_{1} G_{t-1}+\emptyset_{2} G_{t-2}+\varepsilon_{t}
$$

Where $\mathrm{G}_{\mathrm{t}}, \mathrm{G}_{\mathrm{t}-1}$ and $\mathrm{G}_{\mathrm{t}-2}$ represent the present and lagged $\mathrm{GAP}, \varepsilon_{t}$ the error term.

\section{Stationary test results}

However, to estimate equation 23 , the stationary of the individual time series $\mathrm{G}_{\mathrm{t}}$ is required. The stationary test results for unemployment GAP series shown in table 4 indicate that, according to ADF the Individual quarterly time series of $\left(G_{t}\right)$ is stationary in level at $5 \%$ of confidence and at $10 \%$ of confidence for PP while it is stationary at $1 \%$ level of significance according to KPSS test.

Table3: Unit root test results for individual quarterly time series of unemeployment gap(G), through the period 1998 to 2015

ADF test $\quad \mathrm{G}_{\mathrm{t}}$

$\begin{array}{ll}\text { t-statistic in levels } & -3.0444^{* *} \\ \text { t-statistic in first differences } & -4.1157^{* * *}\end{array}$

\section{Phillips-Perron test}

Adj t-statistic in level

Adj t-statistic in first differences

KPSS test

LM stat in level

$0.2129 * * *$

Note: $* * *$, and $* * *$ show the statistical significance at the $10 \%, 5 \%$, and $1 \%$ level of significance respectively Source: Calculated by the author

\section{Regression Estimation results}

Since the individual $G_{t}$ time series is I(0), Equation 23 is estimated by OLS method. The estimation results (equation 24) indicate that both coefficient of the unemployment GAP ( $t=-1$ and $t=-2)$ are significant with a P-value respectively equal to (0.0000) and (0.0000). The R-squared value indicate that the past values of the unemployment GAP explain $98.31 \%$ of the present unemployment GAP changes.

$$
G_{t}=1.70 G_{t-1}-0.83 G_{t-2}
$$

The estimated coefficients indicate that the GAP in time $t=-1$ has high positive impact on the current gap while the gap in time -2 has a lower negative impact on the current gap. Therefore, the unemployment is not persistent but decreases two quarter ahead.

Figure 3 presents the unemployment gap evolutions which reflect. Figure 3 shows that the GAP presents a regular sinusoidal movement with moderate length fluctuations but for the period Q12006-Q12008. A positive gap indicates that the actual unemployment is higher than its natural rate while, a negative gap represents an unemployment under its natural rate. The gap evolution reveals that over the studied period witch count 18 years, the unemployment level was above its natural level for 11 years lowering the economic growth. However, Four main points characterize the studied period. The gap rises steadily in the first quarter of the year 1998 indicating an increase in unemployment over the natural rate with the decrease in inflation after the adoption of the fixed exchange rate regime. The second point is the runup in unemployment over the natural rate after the Assassination of prime Minister Rafic Harriri in 2005 and the Israelite's attack in 2005 to reach a pick in first quarter of the Year 2007. The third point is the slight decrease in unemployment to hit a bottom in q1-2009 with the capital inflows to Lebanon aftermath the international financial crises and to remains under its natural rate during the period Q12008-Q12012 with the decrease in interest rate. The fourth point is related to the increase in unemployment starting 2014 caused by the disturbances in Syria which generate more exports cost specially for agriculture products and an increase in refugees increasing the available number of workers. 
Figure 3: Unemployment gap evolutions through the period Q,1998 - Q42015

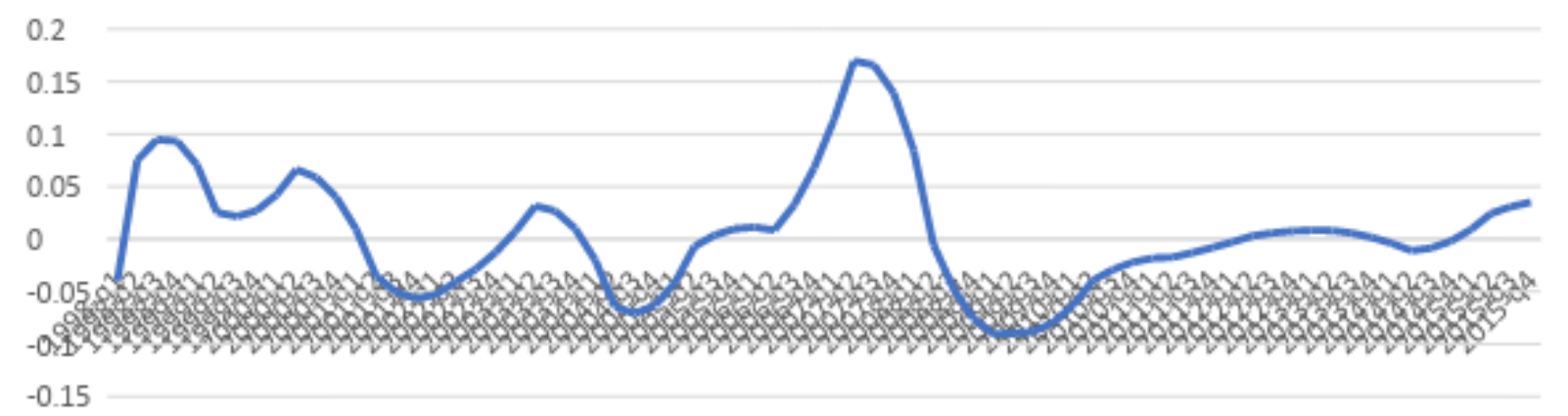

\section{SOURCE: AUTHOR CALCULATION/ GDP DATA FROM WDI}

\subsubsection{TVNAIRU estimation from the Unemployment GAP}

To calculate the NAIRU, the unemployment GAP is considered as unobserved variable. Thus $U_{t}-U^{*}$ is replaced by the cyclical component $G_{t}$ into the Philips curve relationship without inflation expectation equation (12) and with inflation expectations (equation (14),

The unemployment GAP, Gt $=\left(U_{t}-U^{*}\right)$ representing the cyclical component is estimated by the HP filter decomposition. While, $\rho$ the responsiveness of inflation to unemployment, is equal to 8.4558 relatively to previous calculation in this paper. However, since all individual time series are I(0), the OLS method is used to regress the changes on inflation as per Philips curve model.

\section{Philips curve model without including the inflation expectations estimation results}

Including the M2 growth as external supply side shock, the estimation results (equation25) show that the unemployment GAP and the M2 growth are significant to explain the inflation since the respective P-Values are lower than $1 \%$. However, the coefficient have the adequate sign and the R-squared value equal to $27 \%$. Therefore, the estimation of Philips curve model without including the inflation expectations indicates that, a $1 \%$ decrease in unemployment gap implies an $14 \%$ increase in inflation.

$$
\begin{gathered}
\Delta \pi_{t}=1.72-14.01 G_{t}+20.40 Z_{t} \\
\mathbf{( 0 . 0 0 0 0 )}(\mathbf{0 . 0 0 9 0 )} \mathbf{( 0 . 0 0 0 4 )}
\end{gathered}
$$

Including the oil price as External shock, the unemployment GAP remains significant to explain the inflation changes with an interval of confidence equal to $1 \%$ (P-value 0.0015 ) with lower elasticity to inflation changes than considering the money supply as external shock. While the oil price shock, become non- significant.

$$
\begin{gathered}
\Delta \pi_{t}=2.24-13.43 G_{t}+0.003 Z_{t} \\
\mathbf{( 0 . 0 0 0 0 )} \mathbf{( 0 . 0 0 1 )}(\mathbf{0 . 8 6 6 9 )}
\end{gathered}
$$

However, when including both variables, M2 growth and oil price shock, as external shocks in the same equation, both the unemployment GAP and the M2 growth remain significant, but, the oil price shock variable become insignificant.

\section{Philips curve model including the inflation expectations estimation results}

The estimation of Philips curve after including the inflation expectations with money growth and respectively oil price variations as external shocks equations (27 and 28), show that all variables are insignificant to explain the inflation changes in Lebanon.

$$
\Delta \pi_{t}=0.27+1.70 \Delta \pi_{t-1}-0.81 \Delta \pi_{t-2}+1.52 G_{t}+0.13 Z_{t}
$$




$$
\Delta \pi_{t}=0.27+1.70 \Delta \pi_{t-1}-0.81 \Delta \pi_{t-2}+1.58 G_{t}-0.001 Z_{t}
$$

Thus, to estimate the NAIRU, we consider the Philips curve model without including inflation expectation with the money supply growth as external which is the most adequate feature for quarterly data.

$$
\begin{aligned}
& \Delta \pi_{t}=1.725188-14.01702 G_{t}+20.40120 Z_{t} \\
& \Delta \pi_{t}=1.725188-14.01702\left(U_{t}-U^{*}\right)+20.40120 Z_{t} \\
& \Delta \pi_{t}=1.725188-14.01702 U_{t}+14.01702 U^{*}+20.40120 Z_{t} \\
& \Delta \pi_{t}-1.725188+14.01702 U_{t}-20.40120 Z_{t}=14.01702 U^{*} \\
& U^{*}=\frac{\Delta \pi_{t}-1.725188+14.01702 U_{t}-20.40120 Z_{t}}{14.01702}
\end{aligned}
$$

Figure 4 shows the four calculated NAIRU over the studied period from Q,1998 to Q42015, the NAIRU calculated by HP filter (HPU), the constant NAIRU (CTU) and the time varying the NAIRU computed as NAIRU estimation from long-term and short-term shifts (LT-LS) and the NAIRU estimation from the unemployment GAP (GU). The four calculated NAIRU have the same decreasing trend, but the constant NAIRU, and are closely related with the more similarity shown with the NAIRU computed from HP filter and the NAIRU estimation from long-term and short-term shocks. The constant NAIRU is however the highest NAIRU while the NAIRU calculated from the unemployment gap shows the most variation movement.

Figure 4 The four calculated NAIRU for the Lebanese economy from Q,1998 to Q42015.

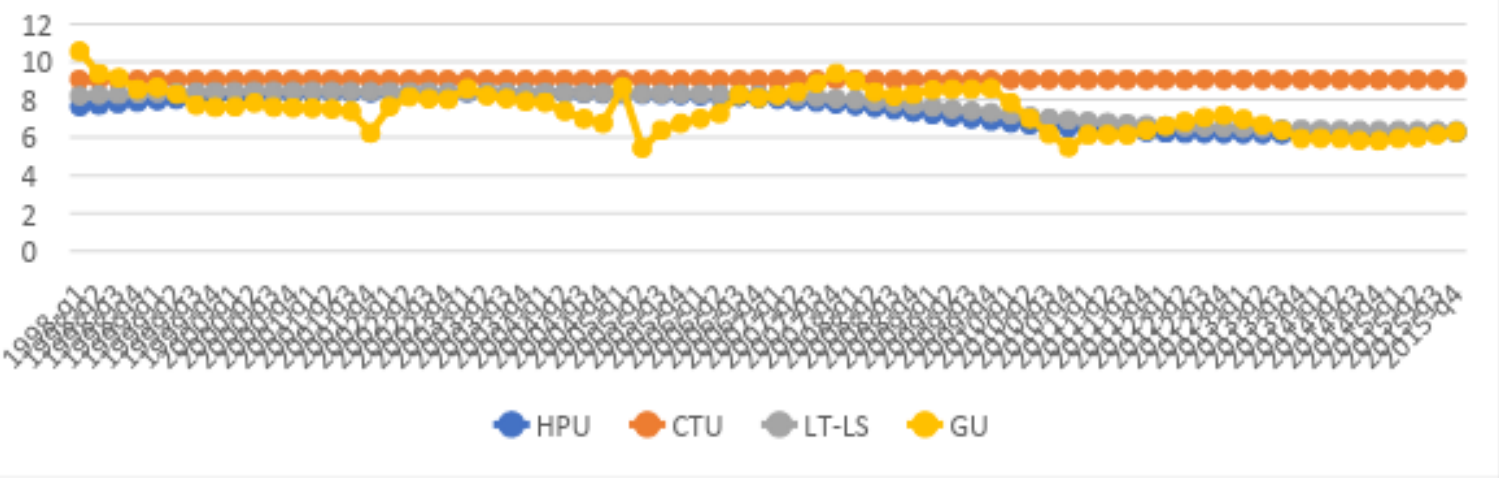

Source: Author calculation

The NAIRU calculated from unemployment gap fluctuations allows to analyze the relationship between unemployment and inflation. The NAIRU concept suggests that when the observed unemployment rate is below the NAIRU, conditions in the labor market are tight and there will be upward pressure on wage growth and inflation. The monetary policy is therefore inefficient. When the observed unemployment rate is above the NAIRU, there is spare capacity in the labour market and downward pressure on wage growth and inflation. Figure 5 shows the NAIRU calculated from unemployment gap, the actual unemployment and the inflation rate over the studied period. It confirms the NAIRU concept for the Lebanese Economy as well as the relation between inflation and unemployment revealed by the previous NAIRU calculation. During the period $\mathrm{Q}_{1}-1998$ to $\mathrm{Q}_{4}-2001$ the unemployment rate was above the NAIRU making downward pressure on inflation. Starting $Q_{1}-2002$, the NAIRU begin to increase and reach as well as the inflation a pick in the fourth quarter of 2002 while unemployment was moving below the NAIRU. From the fourth quarter 2001 to the third quarter 2013 the same story is repeated three times. The consecutive steps of the story are a decrease in the NAIRU and inflation rates with unemployment moving above the NAIRU and then after an increase in NAIRU and inflation rates to touch a pick when unemployment is at its lowest level below the NAIRU. Thus, the NAIRU is an accurate inflation forecasting tool with an acceptable lag difference for the Lebanese economy.

However, the highest level of inflation is registered in the first quarter of 2009 coupled to the highest level of the NAIRU while the unemployment was stable. Since during and aftermath of the international financial crisis, in one hand, a negative shock hits the Lebanese economy with the increase in import prices rising the production cost increasing unemployment and slowing the economic growth. In the other hand, the international financial crises generates capital inflows to Lebanon. Thus, to stabilize the Lebanese exchange rate and maintain the fixed exchange rate regime, the 
Lebanese Central Bank increases the money supply and reduces the interest rate. As consequences, the inflation runup while, the increase in unemployment rate caused by the negative import price shock is compensated by the reduction of unemployment generated by the increase in money supply.

Figure 5: Unemployment rate compared to the actual NAIRU calculated from unemployment gap and the inflation rate from $Q_{1} 1998$ to $Q_{4} 2015$

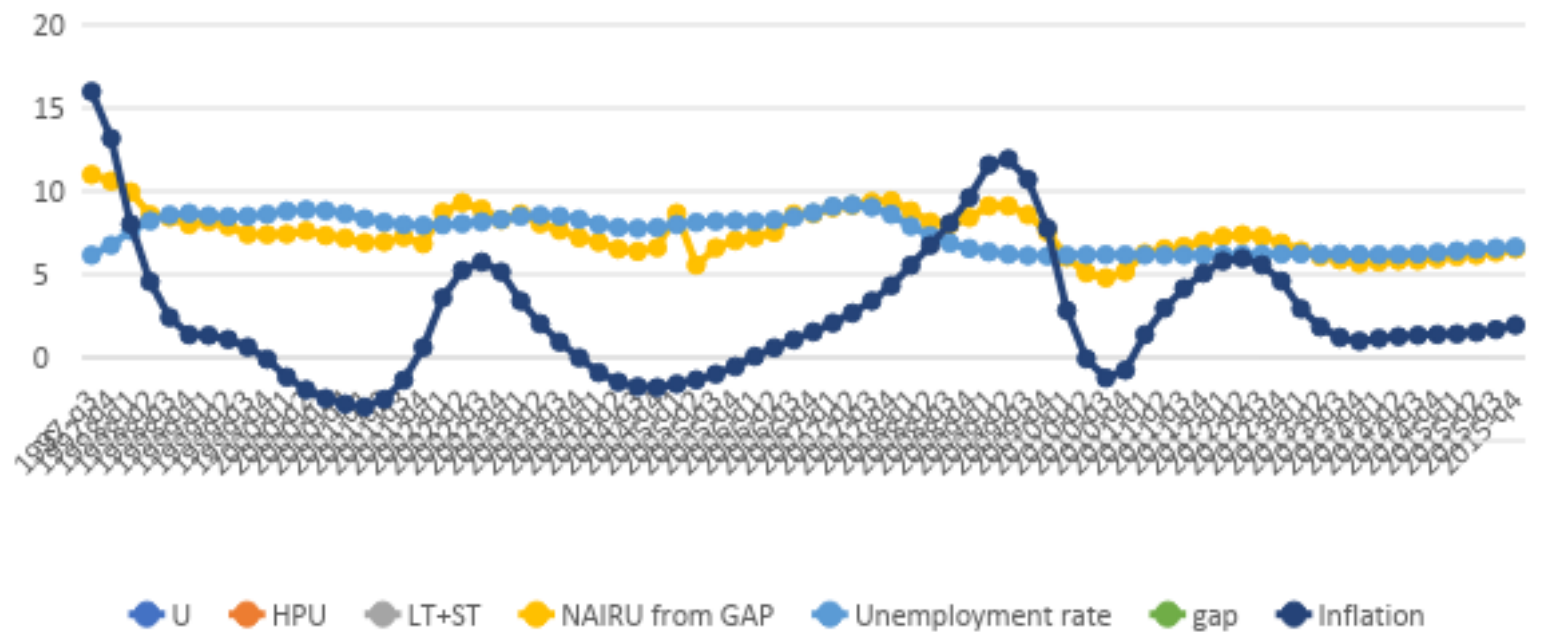

Source: Author calculation

\subsubsection{The Potential Labor adjusted to the unemployment gap}

The potential Labor is modeled by equation (10) and compared to actual Labor in figure 7. The actual employment is moving over the potential Labor during most of the studied period making pressure on economic growth. In other term, since the physical labor hits its limits, enhancing economic growth requires the increase in labor productivity.

Figure 7: The actual and the potential employment level of the Lebanese economy from Q 1998 to Q 2015

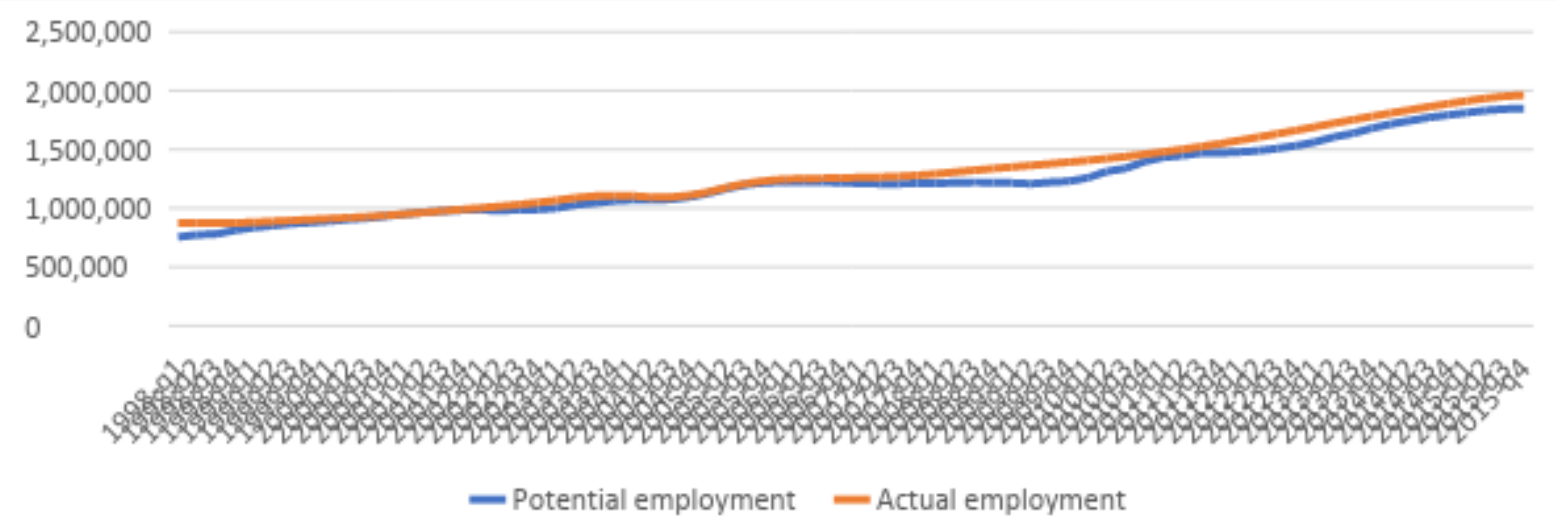

\section{Source: Author Calculation}

\section{5..2.2.9 Potential output and Business cycle identification}

The potential output equation derived from equation (6) and the calculated elasticity of capital and Labor is given the following equation:

$$
\log \left(Y_{t}\right)^{*}=\log \left(A_{t}\right)^{*}+\log \left(K_{t}\right)+0.78 \log \left(L_{t}\right)^{*}
$$

The resulted Potential Output compared to Output calculated through HP-filter and actual Output in figure 8 show that the actual Output is over the potential output for the studied period but during the second quarter of 2005- the first quarter of 2007. In other terms, for all the studied period, the Lebanese economy is working over its capacity but during 
and aftermath the assassination of Prime minister Rafic Harriri in the first quarter of 2005 and the Israelite's attack to Lebanon in the second quarter of 2006.This result confirms the previous results about the actual labour which is higher than potential labor. Thus Lebanese economic growth is freined since the non possibility to increase the labor and capital level leading to the steady state. Therefore, the lebanese effort should concentrate the technological progress (the total factor productivity) to recover the economic growth.

This analysis is however completed by the output GAP analysis. The Output gap is measured by subtracting the estimated potential Output level from its actual level. The generated are business cycles from. Figure 9 presents the Business cycle movement from the first quarter of the year 1998 to the fourth quarter of the year 2015. The movement of the GDP gap reveals three consecutive complete Business cycles with four different stages each, progressing from one into another, as described by Mitchell (1927): expansion, peak, contraction, and trough.

The first cycle starts in the second quarter of the year 2000 through the second quarter of the year 2003. The second cycle occurred from the third quarter of the year 2003 to the second quarter of the year 2006 and is characterized by a longer contraction stage than the first cycle. The third cycle is the longer one, characterized by a long expansion and contraction stages.

The negative output gap is by the theory mainly caused by an under-utilization of some factor resources while, the positive output GAPs are mainly caused by an over-utilization of a nation' resources. The output Gap are mainly positives but for the period $\mathrm{Q}_{2}-2005-\mathrm{Q}_{1}-2007$ which witnessed political disturbances. Thus, the Lebanese economy is working over its actual capacity. This require a restructuring of Lebanese institution and increasing the total factor productivity.

Figure 8: Actual Output and Potential Output calculated through HP-filter (HP Output) and production function (Potential Output) from $Q_{1} 1998$ to $Q_{4} 2015$

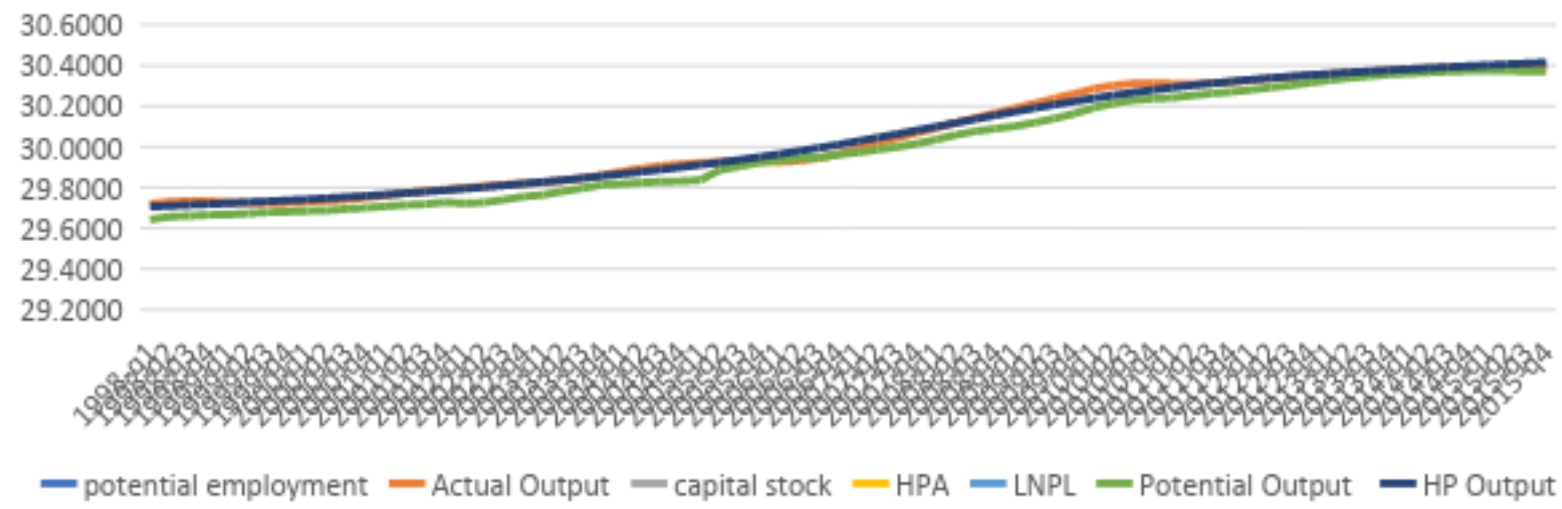

Source: Author Calculation

Figure 9: Business cycles as generated by the production function from $\mathrm{Q}_{1} 1998$ to $\mathrm{Q}_{4} 2015$

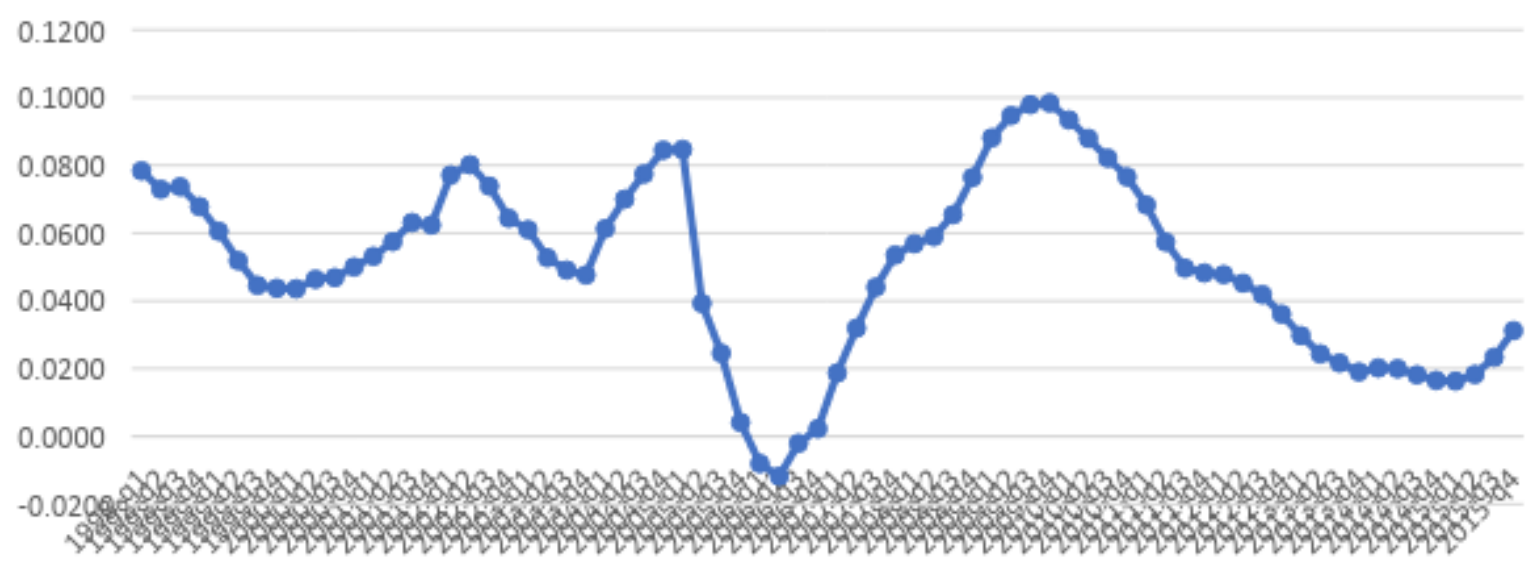

Source: Author Calculation (Real GDP -Potential GDP) 


\section{CONCLUSION}

This research overviews the methods to calculate potential output and applies the production function method to estimate it and generate business Cycle. This method allows the calculation of NAIRU. The NAIRU-or its approximate synonym, the natural rate of unemployment-is an important building block of business cycle theory since, few economists would deny that shifts in aggregate demand, such as those driven by monetary policy, push inflation and unemployment in opposite directions, at least in the short run.

However, the practical application of the NAIRU concept, is not straightforward. The value of the NAIRU is hard to measure, largely because it changes over time. The economy experiences many kinds of shocks This research calculates three types of NAIRU: a NAIRU from a pure statistical method, a constant NAIRU and a time varying NAIRU estimated as long term and short-term shifts and from unemployment gap.

The four calculated NAIRU reveal that the NAIRU decrease over the studied period but the constant NAIRU. Two factors characterizing the Lebanese Labor drive the NAIRU downward trend. The first one is a non-consistent unemployment. This factor is confirmed by the unemployment gap regression which indicates that the unemployment gap is negatively affected by the unemployment two quarter lags. The second factor is the degree of nominal rigidity in labor markets, with this factor affecting the speed of adjustment to changing economic conditions. This factor being related to the low negotiation power for the Union. However, results show that the NAIRU from unemployment gap appears to fluctuate the most and is considered in potential labor calculation.

In the other hand the output gap estimates indicate that the economy performed above it potential for most of the studied period. The positive gap between actual output and potential output indicate that the Lebanese economy is operating over its capacities. The Lebanese economy should make a structural improvement in TPF to not reach the steady state. Thus, any policy aimed at increasing economic growth, while neglecting to address the various structural problems (specifically in the labor market) in the economy, will prove to be unsustainable. 


\section{REFERENCES}

Arrow, K.J., Chenery, H. B., Minhas, B.S., and Solow, R. M. (1961) "Capital-labor substitution and economic efficiency". Review of Economics and Statistics 43: 225-50. 1961

Ball, L, and Mankiw. N.G (2002). "The NAIRU in Theory and Practice." Journal of Economic Perspectives 16(4): 115-136

Blanchard, O.J. and Quah, D. (1989). "The dynamic effect of aggregate demand and supply disturbances". American Economic Review, No. 79

Burmeister, E. and Wall K. (1982). "Kalman filtering estimation of unobserved rational expectations with an application to German hyperinflation". Journal of Econometrics 20(2):255-284, DOI: 10.1016/0304-4076(82)90021-5

Butler, L. (1996). “A Semi-Structural Method to Estimate Potential Output: Combining Economic Theory with a Time-Series Filter". The Bank of Canada's New Quarterly Projection Model, Part 4. Technical Report No. 77. Ottawa: Bank of Canada

Canova, F. (1999), "Does detrending matter for the determination of the reference cycle and the selection of turning points?", The Economic Journal, No. 109.

Cerra, V. and Saxena, S.C. (2000). "Alternative Methods of Estimating Potential Output and the Output Gap: An Application to Sweden". IMF Working Paper, WP/00/59

Chen, J. et al. (2001) "Purification and characterization of the 1.0 MDa CCR4-NOT complex identifies two novel components of the complex". J Mol Biol 314(4):683-94

Christiano, L., Eichenbaum, M. (1992). "Interest Rate Smoothing in an Equilibrium Business Cycle Model," Northwestern University, Unpublished Manuscript

Clarida, R. and Gali, J. (1994). "Sources of real exchange rate fluctuations: how important are nominal shocks? Proceedings". Federal Reserve Bank of Dallas, issue Apr

Cogley, T and Nason, J.M, (1995). "Output Dynamics in Real-Business-Cycle Models," American Economic Review, American Economic Association, vol. 85(3), pages 492-511, June

Cobb, C.W. and Douglas, P.H. (1928). "A Theory of Production. American Economic Review”, 18, 139-165.

Cohen, J, Dickens, W.T, and Posen, A (2001). "Have the New Human Resource Management Practices Lowered the Sustainable Unemployme nt Rate?" In The Roaring Nineties: Can Full Employment be Sustained? Ed. Alan B. Krueger and Robert M. Solow, 219-259. New York: The Russell Sage Foundation and the Century Foundation Press

Cotis J.P, Elmeskov, J. and Mourougane, A. (2005) "Estimates of potential output: benefits and pitfalls from a policy perspective", in L. Reichlin (ed.), Euro area business cycle: stylised facts and measurement issues, CEPR

Cuthbertson, K., Hall, S.G. and Taylor, M.P. (1992). “Applied Econometric Techniques”. Harvester Wheatsheaf

Friedman, M. (1968). “The Role of Monetary Policy.” American Economic Review. March, 58, pp. 1-17.

Fuentes, R., and Morales, M. (2007). “Measuring TFP: A Latent Variable Approach”. Central Bank of Chile Working Papers, No. 419 Granger, W.J and Newbold, P. (1974). "Spurious regressions in econometrics”, Journal of Econometrics, vol. 2 (2), 111-120.

Gordon, Robert J. (1997). "The Time-Varying NAIRU and its Implications for Economic Policy". Journal of Economic Perspectives 11(1): 11-32.

Hamilton, J.D. (1994). "Time Series Analysis. Princeton". University Press

Harvey, A. C. (1992). "Forecasting, Structural Time Series Models and the Kalman Filter". Cambridge University Press, Cambridge Harvey, A.C. and Jaeger, A. (1993). “Detrending, Stylized Facts and the Business Cycle”. Journal of Applied Econometrics, Vol. 8 Hodrick, R. and Prescott, E.C. (1997). “Postwar U.S. Business Cycles: An Empirical Investigation”. Journal of Money, Credit, and Banking, 29 (1)

Kalman, R.E. (1960). “A New Approach to Linear Filtering and Prediction Problem. Transaction of the ASME".Journal of Basic Engineering, 35-45. 
https://doi.org/10.30585/icabml-cp.v2i1.205

(C) 2018 the Authors. International Conference On Advances In Business Management And Law 2018

King, R., C. Plosser and S. Rebelo "Production, Growth and Business Cycles: I. the Basic Neoclasical Model" Journal of Monetary Economics, 21: 195-232, 1988.

Juillard, M., Kamenik, O., Kumhof, M. and Laxton, D. (2006). “Measures of Potential Output from an Estimated DSGE Model of the United States". Working Papers 2006/11, Czech National Bank, Research Department

Laxton, D. and R. Tetlow. (1992). “A Simple Multivariate Filter for the Measurement of Potential Output. Technical”. Report No. 59. Ottawa: Bank of Canada

Lucas, R.J. (1988). "On the mechanics of economic development". Journal of Monetary Economics, 22(3)

Mc Morrow, K. and Roeger, W. (2001). "Potential Output: Measurement Methods, "New" Economy Influences and Scenarios for 20012010 - A comparison of the EU-15 and the US. European Economy". Economic Papers 150, Directorate General Economic and Monetary Affairs, European Commission.

Mise, E., Kim, T. And Newbold, P (2003). “The Hodrick-Prescott Filter at Time Series Endpoints”. University of Nottingham Economics Discussion Paper No. 03/08

Okun, A. M (1962). "Potential GNP \& Its Measurement and Significance”. American Statistical Association, Proceedings of the Business and Economics Statistics Section, 98-104

Phillps, E.S (1967). “Phillips Curves, Expectations of Inflation, and Optimal Unemployment over Time.” Economica. 2:3, pp. 22-44.

Romer, P.M. (1986). “Increasing Returns and Long-Run Growth”. Journal of Political Economy, 103

Sims, C. A (1980). "Macroeconomics and Reality," Econometrica, Econometric Society, vol. 48(1), pages 1-48, January

Solow, R.M (1956). "A contribution to the theory of economic growth". The Quarterly Journal of Economics. 70: 65-94

Solow, R.M. (1957). "Technical Change and the Aggregate Production Function”. The Review of Economics and Statistics, 39(3)

St-Amant, P. and van Norden, S. (1997). “Measurement of the Output Gap”. A Discussion of Recent Research at the Bank of Canada. Technical Reports 79, Bank of Canada

Smets, F. and R. Wouters (2003), "An estimated dynamic stochastic general equilibrium model of the euro area", Journal of the European Economic Association, 1:5 (September), 1123-1175.

Staiger, D, Stock, J.H and Watson, M.W. 1997. "How Precise are Estimates of the Natural Rate of Unemployment?" in Reducing Inflation: Motivation and Strategy. C.D. Romer and D.H. Romer, eds. Chicago: University of Chicago Press, pp. 195-246

Stock, J.H and M Watson (1988). “Testing for common trends “, Journal of the American Statistical Association, 83 1097-1107.

Stock, J.H and M Watson (1999). “Forecasting Inflation.” Journal of Monetary Economics. October, 44:2, pp. $293-335$.

Szeto, K \& Guy M (2004). "Estimating a New Zealand NAIRU," Treasury Working Paper Series 04/10, New Zealand Treasury

Welch, G. and Bishop.G (1995) “An Introduction to the Kalman Filter” Technical Report University of North Carolina at Chapel Hill, NC, USA 